\title{
EL PAPEL DE LAS ILUSTRACIONES EN LOS MANUALES ESCOLARES DE HISTORIA DE ESPAÑA EN LA NARRACIÓN DE LA MEMORIA HISTÓRICA ${ }^{1}$
}

\author{
Gloria Lapeña Gallego \\ Universidad de Murcia
}

http://dx.doi.org/10.5209/NOMA.55462

Resumen: Los manuales escolares de Historia incluyen texto e ilustraciones con la finalidad de transmitir a los jóvenes estudiantes los hechos del pasado. La selección de los temas y su tratamiento ha estado sujeta a la legislación coetánea. El objetivo de este trabajo es realizar una aproximación al conocimiento del papel de las ilustraciones en la transmisión de la Historia de España a través de los manuales escolares. Para ello sometemos a análisis las ilustraciones de tres manuales de dos épocas distintas. El principal resultado encontrado es la sumisión de las ilustraciones al texto, ya de por sí sujeto a control, lo que supone un escaso aprovechamiento del poder evocador de la imagen para llevar al estudiante a la reflexión sobre la Historia.

Palabras clave: Historia, memoria histórica, manual escolar, educación, ilustraciones,

Abstract: History textbooks include text and illustrations for the purpose of transmitting to the young students the facts of the past. The selection of topics and their treatment has been subject to legislation. The objective of this work is to make an approximation to the knowledge of the role of the illustrations in the history textbooks in Spain. For this, we submit to analysis the illustrations of three manuals from two different epochs. The main result found is the submission of the illustrations to the text, already subject to control, which implies a little exploitation of the evocative power of the image to lead the student to reflect on History.

Keywords: History, historical memory, textbook, education, illustrations.

\section{Introducción}

La presentación de los hechos históricos en los manuales escolares, uno de los principales materiales de esta asignatura en enseñanzas medias y básicas, es el resultado de la construcción narrafiva. El filósofo y antropólogo francés Ricoeur, apunta que la Historiografía debe presentarse como un "modo histórico de comprensión. [...] Desde el momento en que la Historia misma entraña una historiografía, tiene visos de artefacto literario" (Ricoeur, 1995, p. 269). La combinación de

\footnotetext{
1 Este trabajo de investigación forma parte de la Tesis Doctoral de la doctoranda Gloria Lapeña Gallego, financiada con una ayuda predoctoral (19099/FPI/13) con cargo al Programa de Formación del Personal Investigador de la Fundación Séneca, Agencia de Ciencia y Tecnología de la Región de Murcia en el marco del III PCTRM 2011-14.
} 
escritura e imagen en los manuales escolares transmite una Historia que no tiene en cuenta todos los grupos sociales, sino que silencia a aquellos que divergen del grupo dominante de cada época. Además, mientras que la manera de presentar el texto, las omisiones y los errores, han sido ampliamente estudiados, no ocurre igual con las ilustraciones que lo acompañan.

El presente artículo tiene como objetivo realizar una aproximación al conocimiento del papel de las ilustraciones en la transmisión de la Historia de España a través de los manuales escolares. Partimos de la hipótesis de que del mismo modo que los textos de estos manuales refleja una Historia institucional en detrimento de la memoria histórica, las imágenes tienen una función aclaratoria o de redundancia por lo que no desarrollan su potencial evocador para la reflexión acerca del pasado.

Para ello, distinguimos, en primer lugar, entre los conceptos hacer historia, asociada a la historiografía bajo control político, y hacer la memoria, que abarca todas las memorias sobre las que se sustenta la Historia. Continuamos con un apartado sobre los manuales escolares de Historia de España y las características de la escritura y ponemos de relieve el papel de las ilustraciones elaboradas o escogidas para acompañar los textos históricos. Para ejemplificar y confirmar nuestra hipótesis de partida, realizamos un análisis cualitativo de las ilustraciones, tomando manuales escolares pertenecientes a dos periodos. Por último exponemos las conclusiones del trabajo.

\section{La Historia institucional y la memoria histórica}

Las fuentes de la Historia, documental y recuerdo, enfrentan dos modos aparentemente opuestos de producción de las representaciones y del conocimiento a la hora de hacer historia o hacer memoria respectivamente (Crenzel, 2010). La inclinación hacia uno u otro tiene que ver con el aspecto selectivo y modo de ordenar la historiografía, puesto que la Historia es siempre la misma (Felman y Laub, 1992). Algunos historiadores, como Giovanni Levi, son partidarios de escribir acerca de todos los hombres, de la sociedad en toda su extensión, no solamente de los reyes y de los grandes personajes, y de la totalidad de las historias que conforman la Historia (Muñoz Arbeláez y Pérez Pérez, 2010). Se rechaza totalmente el historicismo o aquella historiografía tradicional que olvida a los derrotados con los que la memoria histórica tiene una deuda (Benjamin, 2005).

En el año 2008, una serie de historiadores encabezados por Pierre Nora, publican y suscriben en el diario francés Le Monde un manifiesto conocido como el Appel de Blois, en el cual reclaman libertad a la hora de definir la verdad histórica al margen de las autoridades políticas. El origen del manifiesto tiene lugar en Francia, a raíz de sucesivas 
penalizaciones por incumplimiento de diferentes leyes memoriales que crean ciertas hostilidades entre historiadores y políticos. A excepción de la ley Gayssot, formulada en 1990 para penalizar el negacionismo del holocausto judío, Nora defiende la abolición de todas las leyes memoriales porque suponen una criminalización retrospectiva de la Historia. Considera que la Historia no debe ser reescrita ni por las víctimas ni por sus verdugos, y que dichas leyes no hacen otra cosa que obstaculizar la investigación histórica. En España se entabla un debate parlamentario político durante la tramitación de la Ley de la memoria histórica (Ley 52/2007 de 26 de Diciembre) en el que intervienen historiadores, juristas, políticos y publicistas. Esta Ley se refiere exclusivamente a las víctimas de la Guerra Civil (1936-1939) y de la dictadura de Franco (1939-1975).

Resulta comprensible pensar que la memoria histórica, que no es otra cosa que el acontecimiento histórico silenciado, el de las minorías que deben conservar sus identidades, deba ser mostrada a toda la sociedad del mismo modo que se hace con la Historia de los héroes con la intención de legitimar la Historia. García Cárcel (1994) atribuye la manipulación de la Historia a la propia administración de la memoria 0 del olvido. La elección de unos determinados temas, personajes y épocas va a depender de la justificación que se pretenda dar a partes de la Historia según el poder dominante de cada momento.

\section{Tratamiento de la memoria histórica en los manuales escolares españoles}

A pesar del potencial de la Historia como forma de conocimiento social, esta se ha argumentado tradicionalmente según la ideología más o menos represiva del momento, resaltando los aspectos que convienen y omitiendo la presencia de aquello que no interesa. Este hecho repercute con más fuerza en la población joven y vulnerable que, a través de los manuales escolares, es adiestrada hacia un pensamiento único, encauzado por la normativa correspondiente al Ministerio de Educación v organismo equivalente de cada país.

Los manuales escolares, familiarmente conocidos como libros de texto, son una de las principales vías de adquisición de conocimiento por parte de los estudiantes de la asignatura de Historia. La adaptación didáctica de la historiografía para ser presentada en los manuales escolares y los efectos de la recepción de dicha narración por parte del alumno son los aspectos más analizados (Valls Montés, 2012). Respecto del primero, se pone especial atención en la extensión de los temas tratados, los criterios de selección, la adecuación a la legislación dictada, el modelo historiográfico utilizado, las ausencias de hechos históricos destacables que deberían figurar en el manual y no aparecen, la presencia del lenguaje discriminatorio (principalmente de 
género y etnias) o partidista (ligado a la ideología), los errores cronológicos, de periodización, de nombres de personajes y del transcurrir de los hechos históricos. En cuanto a la recepción de la narración por el estudiante, los estudios se centran en los resultados de evaluación con unos instrumentos didácticos acordes con la etapa educativa a la que está destinado el manual. Otros análisis también tienen en cuenta las imágenes, consideradas capaces de ejercer influencia sobre el joven lector. Sin embargo, suelen referirse solamente a aquellas que funcionan como documentos de la Historia, tales como fotografías coetáneas (Valls Montés, 1995) u obras de la Historia del Arte concebidas en la época a la que se alude (del Valle y Waiman, 2014), por ser las más frecuentes en los manuales.

Si bien un ejemplo significativo en la Historia de España es el de la Guerra Civil, que da lugar a la Ley de la memoria histórica, en su sentido amplio la memoria histórica abarca cualquier etapa. Así, la presencia entre los años 711 y 1492 en la península lbérica de al-Ándalus, un país árabe e islámico, es uno de los elementos más problemáticos para la memoria histórica a partir del siglo XIX. Desde este momento hay dos formas de entender el período andalusí: por un lado, la idea amable y favorable de quienes mitifican al-Ándalus, y por otro, la completa incompatibilidad entre lo andalusí y lo español. En el siglo XIX, el periodo andalusí queda distorsionado por el españolismo, consistente en la afirmación de la identidad exclusiva entre lo católico y lo español, dando origen a la ideología nacional-católica, opuesta al Islam. Además, desde una perspectiva denigratoria, al-Ándalus se origina a través de la invasión árabe ilegítima de España. Se entiende entonces la Reconquista como una lucha de liberación y recuperación del territorio invadido por los musulmanes en 711 . De aquí derivan las connotaciones anti-islámicas características del pensamiento españolista. Como reacción surge la idea de la "España musulmana" que ensalza los valores y aportes culturales, artísticos y literarios de lo andalusí, y pasa a un segundo plano su dimensión foránea, árabe e islámica (García Sanjuán, 2013).

Durante la dictadura franquista el auge de la memoria histórica está asociado al concepto de Reconquista y la Guerra Civil, dentro del soporte ideológico del nacional-catolicismo, queda legitimada como una cruzada contra el marxismo y el ateísmo. A pesar del fin de la dictadura y de la llegada de la democracia, los primeros años del siglo XXI también acogen memorias históricas contrapuestas sobre alÁndalus, alimentadas por el terrorismo islamista desde los atentados del 11-S y seguidos por los de Madrid del 11-M. Los partidos conservadores reactivan el discurso de la Reconquista y la amenaza del Islam. Igualmente, a pesar de la formulación de la Ley de la memoria histórica, aún persiste una división a la hora de plantear el tema de la Guerra Civil lo que tiene su reflejo en los manuales escolares de Historia. 


\section{El texto en los manuales escolares de Historia}

El "Primer Seminario Internacional de Textos Escolares (SITE)", celebrado en abril de 2006 en Santiago de Chile, tuvo como principal objetivo crear un espacio para el intercambio internacional de experiencias e investigaciones sobre los libros escolares de texto. Las cincuenta ponencias se agruparon por temáticas, encuadrándose dentro del Tema 4, "Análisis de contenidos y del discurso en textos escolares", tres ponencias relacionadas con la asignatura de Historia. Si bien las tres se refieren al sistema educativo chileno, pensamos que es importante detenerse en algunas conclusiones que los autores extraen de las mismas. No debemos olvidar que, aunque no coinciden en el tiempo las dictaduras de Franco en España (1939-1975) y de Pinochet en Chile (1973-1990), los dos regímenes presentan similitudes: ambas dictaduras comienzan con golpes militares en contra de la Segunda República Española y el gobierno socialista chileno de Salvador Allende (Chaves Palacios, 2010); el nuevo régimen militar se implanta sobre dos procesos sociales democratizadores de los respectivos países (Jara, 2008); el principal objetivo de la dictadura es la reorganización ideológica de la sociedad para impulsar el nacionalismo, denominado "Nuevo Estado" en España y "Refundación Nacional" en Chile. Se produce una reorganización jurídica, económica, política y cultural que transforma los valores sociales y legitima el nuevo orden que va a permitir la construcción de una hegemonía dictatorial (Jara, 2002).

En una de las ponencias del Seminario, Olivares Felice (2007) plantea la evolución de los conceptos de nación e identidad nacional en la enseñanza de la Historia de Chile durante los siglos XIX y XX. A medida que se van sucediendo los gobiernos, el concepto nacionalista es distinto. En el siglo XIX, el nacionalista es una figura autoritaria, tradicionalista y anti-revolucionaria, y se le presenta al alumno como un soldado. Sin embargo, en el siglo XX se transforma en un ciudadano más democrático. En un estudio similar, Zúñiga Fuentes (2007) analiza en los libros de Historia de Chile el trato que se le da al indígena durante el periodo de la fundación del Estado Colonial, denominado también Conquista. En los libros de la primera mitad del siglo XX los autores se posicionan junto a la figura del conquistador o héroe, y transmiten una imagen negativa del indígena. En la actualidad todavía se manifiesta un cierto obstáculo hacia la introducción de políticas de respeto, aceptación y reconocimiento de la multiculturalidad chilena. Por último, Garrido González (2007) también habla de una selección del conocimiento en los textos escolares de Historia con "cuotas de poder" que tienen como finalidad legitimar la ideología del gobierno. El autor parte del concepto de raza como consecuencia del patrimonio genético de las sociedades y su clasificación, más o menos autorizada, en "superiores" e "inferiores". Esta jerarquización se basa en 
argumentaciones racistas asociadas a una explicación biológica sobre la diversidad en los textos escolares de Historia de $7^{\circ}$ y $8^{\circ}$ en los años comprendidos entre 1981 y 1994.

Los libros de texto de Historia de España corren la misma suerte que los de Chile, ya que en ellos también se refleja la huella del control dictatorial que ha atravesado el país. Durante la dictadura franquista, la editorial Miñón edita la Enciclopedia Álvarez, escrita por el maestro Antonio Álvarez Pérez. El principal objetivo del libro, estudiado desde 1950 a 1965 por el 85\% de los niños de las escuelas de España (Niño, 1996), es extender la ideología del Régimen. El Ministerio de Educación Nacional confecciona un programa educativo para la enseñanza en valores de todos los niños. Los textos de Historia de España son utilizados para el enaltecimiento del espíritu religioso católico y lo español como nación. Una especie de maniqueísmo que pretende crear una sociedad con un ideario común opuesto a la multiculturalidad. En el Tercer Grado de esta Enciclopedia, reeditada en facsímil en 2004, podemos encontrar las siguientes expresiones que, de manera sutil, incitan al odio de las diferentes sociedades que "invadieron nuestra península":

Los fenicios se llevaron tantas riquezas de España, que su incansable avaricia determinó la sublevación de los naturales contra ellos (p. 406).

Así era Arabia y así vivían los árabes. Pero un día apareció entre ellos un alucinado llamado Mahoma, que les predicó una nueva religión, y todo cambió por completo, pues fanatizados por sus predicadores, olvidaron rencillas y comenzaron la guerra santa contra los que ellos llamaron infieles (p. 422).

Para castigar los delitos y herejías de los judíos conversos españoles, se creyó conveniente el establecimiento de la Santa Inquisición (p. 445).

Ninguna nación del mundo puede presentar una hoja de servicios tan limpia como la que España puede exhibir, referente a la conquista, civilización y evangelización de América (p. 451).

Con la llegada de la transición y la democracia se diluye la radicalización y alienación ejercida por la Autoridad en Educación. Previamente a la muerte de Franco se desarrollan algunas editoriales, como Santillana o Anaya que, junto a otras anteriores, como SM O Edelvives, crean nuevos textos escolares que tratan otros aspectos de la Historia, como la economía y la sociedad. En su Tesis Doctoral titulada Trato y maltrato de la Historia de España en los libros de texto de la EGB y la ESO, Rodríguez Garrido (2012) realiza un estudio minucioso de la Historia transmitida por los libros de texto españoles en función de las distintas circunstancias políticas, llegando a la conclusión de que, dependiendo de quién se encuentre gobernando en cada momento, los distintos personajes históricos han salido mejor o peor parados, aún en pleno siglo XXI. Otros autores (Cadaveira y Cañuelo, 2014) apuntan 
que la alienación que se impone en los manuales puede corregirse, puesto que la Historia como ciencia solo se convierte en conocimiento escolar cuando el profesor lo transforma en algo enseñable. Por tanto, no solo sería cuestión de modernizar los contenidos del libro, sino de actualizar la concepción de la misma, donde juegan un papel importante el profesor y la propia sociedad (Valls Montés, 2001). En otro estudio (2012) este mismo autor considera que habría que recurrir incluso a otras fuentes, como reglamentos, memorias de centros, testimonios orales, lecturas complementarias, cuadernos de clase, y especialmente actividades paralelas propuestas por el docente.

\section{Las ilustraciones en los manuales escolares de Historia}

El texto del manual escolar de Historia, generalmente va acompañado de imágenes, un elemento capaz de aportar información. llustración es un término genérico que comprende todas las formas de representación, todos los documentos que no son textos (Otlet, 2007). El Diccionario Akal de estética sitúa el uso del término ilustración en el primer tercio del siglo XIX, e insiste en el valor etimológico de ilustrar como "hacer más claro, más inteligible, dar un chispazo de luz" (Souriau, 1998, p. 667). Tradicionalmente, la ilustración es considerada una herramienta que ayuda a captar el interés de los jóvenes hacia la lectura (Venegas, 2012), por lo que se incluye en libros infantiles y juveniles. En ellos, las imágenes representan sin profundidad lo ya dicho por el texto, con el fin de que cuando el adulto lea la historia al niño, este pueda reconocer los distintos elementos gráficos al asociar los colores, formas, tamaños y texturas. A medida que aumenta la edad lectora, la palabra va ganando presencia y la imagen termina por desaparecer. En el punto más bajo de esta escala ocupa solo el lugar de la portada y cumple la función de reclamo.

El manual escolar ilustrado tiene una larga tradición estética. Inicialmente, las páginas escritas incluyen algunos grabados y dibujos a una sola tinta con escaso atractivo. En los libros del siglo XIX, las ilustraciones destacan por su estilo realista de calidad reconocida. Durante las primeras décadas del siglo XX, el uso del color da lugar a bellas ediciones de editoriales españolas como Aguilar, Araluce, Calleja, Juventud y Ramón Sopena (Bertomeu, 2006). Al mismo tiempo, se establecen de manera progresiva determinados códigos de relación texto-imagen y reglas técnico-artísticas en las que interviene un equipo de escritores, ilustradores, diseñadores y editores, con la finalidad de que la iconografía también reproduzca un mensaje.

La función instructiva o didáctica de las ilustraciones, además de la estética, hace que su inclusión en los manuales escolares sea objeto de análisis. La justificación de los estudios de investigación sobre este tema viene dada por la importancia cuantitativa de las imágenes que, 
dependiendo de la edad de los lectores, ocupan una superficie que va desde el cincuenta por ciento hasta casi la totalidad de la página en el periodo de pre-lectura e inicio de la lectura. Además, cada una tiene un peso específico en cuanto al mensaje que transmiten y su adecuación con el texto que complementan. Su función nunca es arbitraria. Como mínimo tienen un componente pedagógico y científico, y en ocasiones no son neutras desde el punto de vista político e ideológico.

En los manuales de Historia de España, las ilustraciones que acompañan al texto y a las actividades propuestas, junto con las aclaraciones y las lecturas complementarias, son relevantes en la medida en que influyen en la interpretación de la historiografía (Valls Montés, 2012). Por tanto, el análisis de las ilustraciones puede indicarnos el grado de intervención que el Estado ha tenido en la transmisión de valores (Valls Montés, 1995), dado que son un medio privilegiado de propaganda del ideario, especialmente en una población vulnerable por su juventud.

La mayoría de los estudios sobre las ilustraciones de los manuales están realizados por pedagogos y educadores que, de manera general, analizan las posibilidades didácticas resultantes de la combinación de la escritura con la imagen y la correlación entre ambas, especialmente en Educación Infantil y Primaria. A medida que avanzamos en las diferentes etapas educativas, Secundaria y Bachillerato, es más frecuente encontrarnos con estudios realizados por especialistas de una materia concreta. En el caso de las asignaturas fundamentadas en una metodología experimental, como la Biología, la Física o las Matemáticas, se busca un rigor formal y semántico de las ilustraciones, es decir, se analiza qué ideas y significados transmiten al lector (Prieto Velasco, 2007).

Las publicaciones sobre análisis de las imágenes en los manuales de Historia son escasas, puesto que la responsabilidad en la transmisión de información recae principalmente en el lenguaje escrito. No obstante, Valls Montés (2012) realiza una clasificación de las imágenes que acompañan al texto de Historia y distingue entre ilustración y documento según la función ejercida. Las ilustraciones son imágenes decorativas y emotivas subordinadas del texto escrito, no aportan nada nuevo y pueden ser eliminadas del manual, e incluso en ocasiones resultaría aconsejable suprimirlas para no provocar esas comprensiones anacrónicas. La función de la ilustración según su significado etimológico de aclarar o iluminar no se cumple, por lo que no es una denominación muy acertada para este grupo de imágenes que acompañan los textos historiográficos. En cuanto al término documento, Valls Montés lo refiere como una imagen fundamentalmente coetánea que "puede suministrar información sobre una época determinada si se realiza una adecuada lectura de la misma desde la pertinente interpretación de los convencionalismos en que está basada" (Valls 
Montés, 2012, p. 144). El análisis sobre las imágenes propuesto por Valls Montés (2012) se basa, como podemos apreciar, en una visión del conjunto imagen-comentario de la imagen y, respecto de estos últimos, su mayor o menor amplitud y precisión.

En el capítulo VI de su libro (Valls Montés, 2012) presenta un ejemplo de análisis icónico de la Guerra de la Independencia en los manuales españoles de Historia a lo largo del siglo XX. Contabiliza el número de imágenes con el fin de analizar la evolución en los manuales en lo que se refiere a la cantidad de imágenes. A continuación clasifica las imágenes según su función ilustrativa o función documental, centrándose en estas últimas. Concluye que el mayor cambio en las imágenes y en el texto de los manuales analizados se produce a partir de 1975, momento en el cual comienza a darse un equilibrio cuantitativo entre los dos componentes históricos de este periodo: las guerras napoleónicas y la Constitución de Cádiz. Por otra parte, apunta que si bien en la selección de imágenes se ha mejorado, realizando además un esfuerzo por convertir las ilustraciones en documentos, queda mucho camino por recorrer en la incorporación de los análisis iconográficos. Además, llama la atención sobre la necesidad urgente de evaluar la interpretación que da el estudiante a la iconografía que acompaña a los textos, dada la polisemia de las imágenes, y de adoptar una actitud de diálogo en el aula.

Otros análisis se remontan a manuales editados en épocas anteriores. En estos manuales se aprecia más claramente la influencia del poder sobre el texto escrito y las imágenes. Badanelli Rubio (2008) estudia las ilustraciones de los libros de lectura y textos en general de las escuelas primarias más utilizados por maestros y recomendados por inspectores en las aulas durante las dos primeras décadas del franquismo (19401960), con los que se pretende transmitir la identidad nacional, valores e ideología. El $50 \%$ de estos libros son de Religión o incluyen en su título la palabra "España". Para este trabajo, la autora utiliza la clasificación de Colas Bravo y Corts Giner (1990), que divide las imágenes de los manuales escolares en seis grupos: explicativa, motivadora, vicarial, catalizadora de experiencias, nemotécnica y decorativa. Las funciones de la mayoría de las ilustraciones de los libros que analiza son explicativas del texto en tanto que aclaran, y motivadoras por acercar realidades ajenas al niño. Sin embargo, no aparecen representadas imágenes catalizadoras de experiencias para ejercitar al alumno en alguna actividad, siendo el cien por cien de los contenidos memorísticos. Se destaca el papel de las imágenes en la creación de identidades: hombres formados en la resignación (trabajo, autoridad en la familia), mujeres virtuosas (en casa, oración) y ambos con obediencia a la autoridad legítima (la Patria, representada por la bandera y el escudo). 


\section{Estudio del papel de las ilustraciones en manuales escolares de Historia de España}

En base a todo lo expuesto y como aportación personal a este estudio, sometemos a análisis tres manuales escolares de Historia de España. Uno correspondiente a la época franquista y dos actuales de diferentes editoriales.

Tenemos en cuenta que el manual escolar o libro de texto de Historia es la principal fuente documental para la adquisición de conocimiento por parte de los jóvenes estudiantes de niveles de enseñanza obligatoria. Su carácter de adoctrinamiento puede llegar a constituir una herramienta para favorecer al poder de cada presente, lo cual ha tenido también repercusión generalizada en las ilustraciones de los textos recomendados tradicionalmente en las escuelas primarias del franquismo, y en particular en los contenidos de Historia, como hemos podido comprobar en el estudio sobre esta sección de la Enciclopedia de Álvarez, publicación cuyas ilustraciones serán el primer objeto de análisis.

A pesar de encontrarnos lejos, tanto en el tiempo como en ideología, de la dictadura que nos antecede, los mensajes subliminales y omisiones en las imágenes de los manuales de Historia vigentes persisten y se manifiestan en un mayor o menor grado, dependiendo de la orientación política de la propia editorial. Para evidenciar este hecho, analizamos tratamiento dado por dos editoriales distintas a las ilustraciones del capítulo de la Guerra Civil española (1936-1939). La importancia de la imagen de este hecho histórico está justificada por dos hechos. Por una parte, es la primera contienda del siglo XX fotografiada en directo por cámaras ligeras, de forma que las instantáneas llegaban a los periódicos extranjeros con rapidez. Por otro, se produce una guerra paralela para movilizar a la población. Este segundo aspecto propagandístico ha tenido posteriormente gran importancia a través de los medios de comunicación de masas, pero lo innovador es la intensidad con la que se produjo a través de la imagen (Llorente Hernández, 2009). Para la elaboración de este capítulo del manual de Historia de España, existe una amplia variedad de imágenes que ofrece la posibilidad de elección.

\section{El manual escolar de Historia durante la dictadura de Franco}

Con la finalidad de obtener datos sobre las ilustraciones del manual más utilizado durante el periodo franquista, hemos tomado la Enciclopedia Tercer Grado (Álvarez Pérez, 1966), que agrupa todas las asignaturas de la etapa educativa correspondiente a los 12-15 años (Bachillerato), antes de la Reforma de 1970. En este periodo histórico la educación fue un medio de adoctrinamiento político y religioso. El texto contó con la aprobación de las autoridades civiles y eclesiásticas, que "desecharon 
todas las publicaciones contrarias a los principios de la religión y de la moral cristiana, la represión también afectaría a las imágenes que debían esclarecer la Historia" (Valls Montés, 2012, p. 71). La Enciclopedia Álvarez es, además, una obra en la que la autoría del texto, ilustraciones y caligrafía recaen sobre la misma persona, incidiendo continuamente en duplicidad o redundancia informativa e ideológica a lo largo de todo el manual. Analizamos en su conjunto la asignatura de Historia, resumida en noventa y tres páginas, para conocer el modo selectivo en que se escogen las ilustraciones que acompañan y se someten a los textos, ya controlados previamente por el régimen dictatorial.

Podemos apreciar que las imágenes, todas en blanco y negro, son, según el concepto de Valls Montés (2012), ilustraciones, y su función es explicativa o motivadora según la clasificación de Badanelli Rubio (2008). En su mayoría representan supuestos retratos de héroes de cabeza cubierta por armadura de guerra, siempre de perfil, resaltando el carácter de hombre firme a sus principios. Los santos, por el contrario, se muestran de frente, más apacibles y serenos, y con la cabeza descubierta rodeada de una aureola. Las escenas bélicas siempre hacen referencia a los conceptos de "morir por la defensa de la religión" o "por la Patria", que como hemos apuntado coinciden con la ideología del nacional-catolicismo, contrario a la memoria histórica de al-Ándalus. En toda la parte correspondiente a la Historia solamente aparecen representadas en esta Enciclopedia cuatro mujeres, de las que se resalta su patriotismo, abnegación y catolicismo: dos reinas (Isabel la Católica e Isabel II), una heroína (Agustina de Aragón) y una santa (Santa Teresa de Jesús). Como escribe Álvarez en el prólogo de uno de los manuales de primer grado de Historia (Agustín Serrano de Haro, citado por Álvarez-Sanchís y Ruiz Zapatero, 1998):

Queremos que (los alumnos) empiecen a oír los nombres ejemplares de las gestas heroicas; de las cosas de Dios y de España entren, como sal de bendición, en la levadura germinal de su conciencia. Más no precisamente para que sepan. Todo no ha de consistir en saber... lo que importa es que la lección cale hasta lo hondo y deje las entrañas temblando de emoción.

Estas palabras corresponden a 1943, cuando los escolares no tenían más imágenes que las ilustraciones de los libros y las figuras reales de sus maestros, encargados de resaltar los valores de la "raza".

Tras la muerte de Franco, la iconografía de los libros de Historia se centra en la idea de "nación". Campos Pérez (2010) estudia este concepto en los años de la transición democrática (1976-1983) a través de las imágenes de los manuales de Historia, Educación Cívica y Educación patriótica destinados a la enseñanza primaria. De este estudio se extraen como conclusiones la disminución considerable de las representaciones sobre la idea de nación, y su sustitución por la representación de las comunidades. 


\section{Los manuales escolares de Historia actuales}

Los manuales actuales de Historia de Educación Primaria, Secundaria y Bachillerato contienen, en su mayoría, fotografías de archivo e imágenes de obras de arte que recrean personajes y hechos históricos destacados. Diferentes estudios de investigación sobre los aspectos pedagógicos de las imágenes de los libros de Historia establecen pautas para analizarlas (Hernández Cardona, 2011). Cabe destacar el propuesto por Gómez Carrasco y López Martínez (2014) para evaluar los manuales escolares de Historia de $4^{\circ}$ de Educación Secundaria Obligatoria de tres importantes editoriales españolas. Mediante el análisis del uso de la iconografía en las primeras Unidades, los autores valoran si la imagen como recurso didáctico ayuda al alumno a ampliar y complementar su conocimiento sobre Historia. La metodología que utilizan consiste en un análisis estadístico sobre la proporción de imágenes en cuanto a su tipología (obras pictóricas, ilustraciones, fotografías, mapas, tablas, gráficos, líneas de tiempo y diagramas), como en sus funciones con respecto al texto (estética, explicativa, informativa en sí misma y comprobadora de conocimientos). Se trata de estudios centrados en la didáctica de la Historia, de su comprensión y de la aclaración de las ilustraciones a la hora de interpretar los textos para facilitar el aprendizaje.

Con el fin de apoyar y verificar la manipulación en los manuales de Historia detectada por algunos autores, hemos analizado las ilustraciones contenidas en dos manuales vigentes de Historia de España de $2^{\circ}$ de Bachillerato elaborados de acuerdo con la Ley Orgánica 2/2006 de 3 de mayo. La elección de esta etapa educativa se debe a que la asignatura de Historia de España es obligatoria en este último curso de Bachillerato, previo a las pruebas de Selectividad, y por tanto, enfocada a futuros universitarios a punto de alcanzar la mayoría de edad, con una supuesta madurez y criterios propios, ya no tan influenciables por un libro de texto como en la etapa infantil. Sometemos a análisis, como hemos apuntado, la Unidad destinada a la Guerra Civil española (1936-39), periodo inmediatamente anterior a la llegada de la dictadura franquista en España. Es importante considerar que la instauración de la democracia ha sido un proceso paulatino, lo cual nos hace presumir que vamos a encontrar en las ilustraciones el mismo retraso que han apuntado otros autores con respecto a los textos historiográficos de los manuales. La nostalgia por la dictadura de generaciones aún vivas ha tenido consecuencias en la ralentización de una democracia plena, hecho que se hace visible, por ejemplo, en el retardo a la hora de llevar a juicio a los responsables de los crímenes del régimen franquista. En un estudio comparativo en torno a la reconciliación nacional en España y Chile a cargo de la acción judicial del juez español Baltasar Garzón, del que es autora Sophie Baby (2011), 
se pone de manifiesto que la inculpación y detención de Pinochet se lleva a cabo en 1998 (la dictadura chilena finaliza en 1990), mientras que la causa judicial póstuma contra Franco no se inicia hasta 2008. En ambos casos, no obstante, son cuestiones actuales que se plantean en torno a las nociones de justicia, Historia y Memoria, y que tienen su reflejo en la Historiografía de los manuales de cada país.

\section{Manual escolar actual uno}

Uno de los dos ejemplos de manuales escogido para nuestro estudio comparativo acerca de las ilustraciones en los libros de Historia de España vigentes para el $2^{\circ}$ curso de Bachillerato pertenece a un grupo editorial fundado por religiosos marianistas. Si bien este manual no tiene nada que ver con la Enciclopedia de Álvarez, todavía se arrastran algunas reminiscencias del pasado siglo, que tienen su reflejo, entre otros aspectos, en el registro gráfico.

La Unidad en su conjunto contiene un total de veintiséis fotografías de archivo, siete mapas, dos histogramas, y dos carteles propagandísticos de la época. De las veintiséis fotografías de archivo, seis son retratos acompañados de biografías, once son aclaradas mediante pie de foto, con una función en ambos casos de adorno. Las nueve restantes aparecen con pie de imagen y recuadradas junto a un documento histórico para ser comentado por el alumno. Por tanto, se encuadrarían dentro del concepto de documento de Valls Montés, si bien su eliminación no reduciría la información para que el alumno pueda realizar la actividad.

Los seis pequeños retratos están divididos en grupos de tres como "los sublevados" y "los republicanos". Tienen una función estética muy similar a la de los dibujos de la Enciclopedia de Álvarez, consistente en facilitar el aprendizaje memorístico de los textos por asociación.

Las once fotografías son acciones con pie de foto. Sin embargo, en la mayoría no se comenta directamente la fotografía. El pie de una imagen donde aparecen un grupo de jóvenes haciendo el saludo oficial del Régimen, apunta: "La guerra civil interna fue el más trágico epílogo de la tragedia que acabó con la República. Las tropas de Franco entraron en Madrid el 28 de marzo", y el pie de otra imagen de Franco entre otros militares señala: "La cohesión interna del bando rebelde, en comparación con el caos republicano de los primeros meses, fue trascendental para el desenlace de la guerra". Su función es, al igual que las anteriores, puramente estética, según la concepción de Valls Montés (2012).

Las fotografías que aparecen recuadradas acompañando un documento escrito tienen un carácter institucional. Se trata de retratos de medio cuerpo o escenas estáticas de personajes que miran 
directamente a cámara. A pesar de pertenecer a la categoría de documentos, apenas aportan información sobre acciones.

Los mapas e histogramas contienen información en sí mismos. Pertenecen a la Historia científica cuantitativa. En los mapas se reflejan situaciones de las fronteras a medida que van sucediendo los hechos bélicos. Los histogramas valoran la magnitud de la intervención extranjera en España para ayudar a ambos bandos.

Los dos carteles, uno del Régimen y otro del bando republicano están nombrados con un escueto pie de imagen: "Cartel de propaganda franquista" y "Cartel publicitario del bando republicano", respectivamente. En el texto no se hace referencia a estos carteles. Se pueden eliminar sin que se produzca alteración alguna del capítulo del manual, El pie de cada imagen no interpreta nada, ni tampoco invita al alumno a hacerlo. Una de sus funciones principales es la estética o de animación a la lectura, así como facilitadora a la hora de adquirir los conocimientos en una asignatura considerada de aprendizaje memorístico.

\section{Manual escolar actual dos}

La elección para análisis del segundo manual de Historia de España de $2^{\circ}$ curso de Bachillerato viene dada por ser el más utilizado en el año 2000 en todas las Comunidades Autónomas, excepto en la Comunidad Valenciana, donde es superado por otra editorial en tan solo un punto porcentual. Los porcentajes oscilan entre el $62 \%$ en Baleares y el $16 \%$ en la Comunidad Valenciana (Valls Montés, 2012). Por otra parte, en esta misma fuente bibliográfica se reflejan los porcentajes de manuales de Historia de Bachillerato utilizados en los centros de secundaria entre 1982 y 1984. La editorial que vamos a analizar es la primera, con un $53,1 \%$ en centros públicos y un 35,1\% en centros privados. Dentro de estos últimos se incluyen los colegios de carácter propio católico, que en secundaria obligatoria se encuadran en los conciertos de las Consejerías de Educación.

El capítulo de la Guerra Civil incluye seis fotografías de archivo, dos imágenes de obras de arte realizadas durante la contienda, ocho mapas y un total de dieciocho carteles.

Las seis fotografías elegidas para este capítulo, de contenido fundamentalmente bélico, recogen imágenes de vidas paralelas a la contienda, personajes de segundo y tercer nivel que no pertenecen a la Historia oficial. La primera imagen que introduce el capítulo es un plano figura de un miliciano republicano en el momento de su muerte. El pie de imagen refiere el lugar, fecha y autoría de la fotografía, mientras que el protagonista de la narración de la instantánea permanece en total anonimato, como un monumento al soldado desconocido, 
representando a los muchos de "los vencidos" que murieron del mismo modo. Tres fotografías son escenas humanas de personas anónimas (refugiados cruzando la frontera francesa al finalizar la guerra) e incluso irónicas (anarquistas y miembros de la Guardia Civil en una barricada compartiendo comida, dos niños frente a una imagen del Caudillo pintada en una pared haciendo el saludo oficial). Por último, dos fotografías de carácter cultural sobre la Generación del 27 y la compañía de teatro La Barraca se incluyen en una doble página de Pensamiento y Cultura: Una cultura yugulada por la Guerra Civil, junto con las dos pinturas de Salvador Dalí y el cuadro Guernica de Pablo Picasso.

Todos los mapas que ilustran el capítulo de la Guerra Civil de este libro, al igual que algunas tablas y todas las imágenes, están numerados. En el texto están referidos con la abreviatura doc. (documento) seguida del número al que se está haciendo referencia. Al pie de cada mapa se plantean una serie de cuestiones en las que se invita al alumno a extraer conocimientos de la combinación y relación texto-imagen. Así, por ejemplo, en texto que hace referencia a uno de los mapas, enuncia brevemente el tema del Alzamiento Nacional, así como las ciudades donde fracasó y donde triunfó, constituyendo la Historia institucional de la Guerra Civil, lo que es necesario "aprender". La imagen es un mapa de la península bicolor que representa las ciudades en las que prosperó o no prosperó el alzamiento. A través de tres cuestiones, el alumno debe pensar la Historia y hablar de zonas industriales del bando republicano o rasgos sociales de cada bando.

Con los dieciocho carteles, se resalta la explosión creativa con intención propagandística. Suponen un testimonio gráfico unido a la lucha ideológica. Cuatro son nacionales y diez pertenecen al bando republicano. Estos últimos resaltan la unión del trabajador obrero en la lucha, y algunos de ellos muestran un carácter irónico alusivo al régimen. Dentro de este conjunto de imágenes distinguimos un primer grupo formado por aquellas que aparecen referidas en el texto como "documentos", y el alumno debe relacionar el texto con la imagen y reflexionar sobre las cuestiones planteadas. El segundo grupo está formado por tres carteles de cada bando que ocupan dos páginas y que carecen de texto alguno. Se trata de una actividad que, bajo el epígrafe "Métodos de trabajo histórico" tiene la intención de que el alumno analice los recursos iconográficos que utilizan los carteles y los mensajes que transmiten. 


\section{Conclusiones}

La Historiografía o escritura de la Historia ha sido tradicionalmente selectiva en tanto que no escribe acerca de toda la sociedad en su extensión, sino que se basa fundamentalmente en el historicismo, olvidando en mayor o menor medida a los derrotados, con los que la memoria histórica tiene una deuda, lo que tiene su reflejo en los manuales escolares de Historia. Si bien los métodos estadísticos de recuento de imágenes o de clasificación según su principal función pedagógica no ofrecen una información objetiva sobre la calidad historiográfica, resulta evidente el avance en una democratización sociocultural que tiene su reflejo en una mayor libertad de expresión respecto de los manuales de la época franquista. Sin embargo, algunos manuales de Historia no son totalmente neutrales en la actualidad a la hora de elegir las imágenes que acompañan a los textos historiográficos, aunque evidentemente se van acercando hacia el ideal del pensamiento histórico reflexivo y comprometido con la memoria histórica, entendida como una Historia global y multicultural fuera de la ideología política. Así, hemos puesto de manifiesto que mientras que la primera editorial sujeta a análisis subtitula cada fotografía con enunciados que contextualizan el hecho histórico en una fecha y lugar, la segunda muestra una iconografía más propicia para pensar y reflexionar, incluyendo actividades plurales que van más allá del hecho histórico, poniendo en evidencia formas de expresión artística que durante mucho tiempo estuvieron censuradas y perseguidas.

El papel de las ilustraciones, por otra parte, está al servicio del texto y no es aprovechada suficientemente la voz narrativa propia para imaginar otros puntos de vista y otras interpretaciones que no por ello desvirtúan la narración histórica, sino todo lo contrario, complementan e impulsan debates interesantes entre los estudiantes. Resultaría interesante utilizar metodologías que tuvieran más en cuenta la comunicación o manera de presentar la Historia al alumno mediante imágenes. Cabe esperar que si las imágenes han estado supeditadas al dominio del escritor en otros tipos de textos literarios, como la novela y el cuento, en el caso concreto de los manuales escolares de Historia, este hecho se pone aún más en evidencia. La imagen oficial que se ha pretendido transmitir está doblemente apoyada por el texto y por las imágenes elaboradas o seleccionadas para acompañarlo. Este refuerzo viene dado por la repetición que supone la ilustración con respecto del texto. Además, puesto que ni el manual ni el ámbito escolar son, respectivamente, el único documento y entorno para la transmisión y reflexión sobre la Historia, se hace necesario el estudio de otras narraciones y soportes alternativos en los que tanto el historiador como el ilustrador tengan cierta libertad para contemplar otros temas y aspectos de la Historia. 


\section{Referencias Bibliográficas}

Álvarez-Sanchís, J. R. y Ruiz Zapatero, G. (1998). España y los españoles hace dos mil años según el Bachillerato franquista (periodo 1936-1953). Iberia 1, 37-52.

Baby, S. (2011). ¿Latinoamérica: un desvío necesario? Baltasar Garzón, de Pinochet a Franco. Amnis. Revue de civilisation contemporaine Europes/Amériques, 2. doi: 10.4000/amnis. 1485

Badanelli Rubio, A. M. (2008). Ser español en imágenes: la construcción de la identidad nacional a través de las ilustraciones de los textos escolares (1940-1960). Historia de la Educación, 27, 137-169.

Benjamin, W. (2005). Sobre el concepto de Historia. México: Ediciones Contrahistorias.

Bertomeu, C. (2006). El cuento como instrumento para el desarrollo de la creatividad artística. Barcelona: Editorial Jacaryan S.A.

Cadaveira, G. y Cañuelo, G. (2014). Los profesores de historia y el uso de la imagen fija en sus clases: ¿ilustración o fuente? Revista Entramados Educación y Sociedad, 1, 277- 291.

Campos Pérez, L. (2010). Iconografía de la idea de España en los manuales escolares durante la transición a la democracia (1976-1983). Cuadernos de Historia Contemporánea, 32, 109-130.

Crenzel, E. (2010) Historia y memoria: Reflexiones desde la investigación. Aletheia, 1(1), 1-13.

Chaves Palacios, J. (2010). La larga memoria de la dictadura en Iberoamérica. Argentina, Chile y España, Argentina. Buenos Aires: Prometeo editorial.

Del Valle, L. C. y Waiman, D. (2014). Las imágenes medievales en los manuales escolares argentinos. Mirabilia, 19, 1-7.

Felman, S. y Laub, D. (1992). Testimony: Crises of Witnessing in Literature, Pychoanalysis and History. New York: Routledge Taylor and Francis Group.

García Cárcel, R. (1994). La manipulación de la Memoria histórica en el nacionalismo español. Manuscrits, 12, 175-181.

García Sanjuán, A. (2013). La distorsión de al-Andalus en la memoria histórica española. Intus-Legere Historia, 7 (2), 61-76.

Garrido González, C.F. (2007). Visiones racistas en los textos escolares de Historia de $7^{\circ}$ y $8^{\circ}$ básico, en Chile (1981-1994), pp. 169-175. Primer Seminario Internacional de Textos Escolares (SITE). Abril, 2006. Santiago de Chile. 
Gómez Carrasco, C.J. y López Martínez, A.M. (2014). Las imágenes de los libros de texto y su función en la enseñanza de la Historia. Diseño de un instrumento de análisis. Enseñanza de las Ciencias Sociales, 13, 17-29.

Hernández Cardona, F. X. (2011). La iconografía en la didáctica de las Ciencias Sociales, Geografía e Historia. Íber, Didáctica de las Ciencias Sociales, Geografía e Historia, 4, 105-119.

Jara, I. (2002). De Franco a Pinochet. El proyecto cultural franquista en Chile. 1936-1980. Santiago de Chile: Facultad de Artes, Universidad de Chile.

Jara, I. (2008). La ídeología franquista en la legitimación de la dictadura chilena. Revista Complutense de Historia de América, 34, 233-253.

Llorente Hernández, Á. (2009). La batalla de Madrid en el arte español durante la guerra civil y el primer franquismo. Archivos de la filmoteca, 60/61, 6-27.

Muñoz Arbeláez, S. y Pérez Pérez, M. C. (2010). Perspectivas historiográficas: entrevista con el profesor Giovanni Levi. Historia Crítica, 40, 197-205.

Niño, A. (1996, octubre 7). Álvarez, el de la Enciclopedia. El País. Recuperado

http://elpais.com/diario/1996/10/07/madrid/844687466_850215.html

Nora, P. y col. (2008, octubre 11). L'appel de Blois. Liberté pour l'Histoire. Recuperado de:

http://www.lphasso.fr/index.php?option=com_content\&view=article\&id=47\&ltemid=\&la $\mathrm{ng}=\mathrm{fr}$

Olivares Felice, P. (2007). El concepto de nación e identidad nacional: una approche a través de las políticas educativas y de la enseñanza de la Historia de Chile (siglos XIX-XX), pp. 161-165. Primer Seminario Internacional de Textos Escolares (SITE). Abril, 2006. Santiago de Chile.

Otlet, P. (2007). El tratado de documentación. [Traducido por M. D. Ayuso García]. $2^{a}$ ed. Bruselas: Ediciones Mundaneum Palais Mondial.

Ricoeur, P. (1995). Tiempo y narración. Configuración del tiempo en el relato histórico. Méjico: Siglo XXI.

Rodríguez Garrido, J. E. (2012). Trato y maltrato de ta historia de España en los libros de texto de la EGB y la ESO (Tesis Doctoral). Departamento de Didáctica de las Ciencias Sociales. Facultad de Educación. Universidad Complutense de Madrid, Madrid.

Souriau, E. (1998) (2010 primera reimpresión). Diccionario Akal de estética. I. [Traducido por X. Grasa Adé, C. Meilán Pita, C. Mercadal y A. Ruiz de Samaniego]. Madrid: Akal. 
Valls Montés, R. (1995). Las imágenes en los manuales escolares españoles de Historia, ¿̇lustraciones o documentos? íber, Didáctica de las Ciencias Sociales, Geografía e Historia, 68, 7-16.

Valls Montés, R. (2001). Los nuevos retos de las investigaciones sobre los manuales escolares de historia. Revista de Teoría y Didáctica de las Ciencias Sociales, 6, 31-42.

Valls Montés, R. (2012). Historiografía escolar española: siglos XIX-XXI. Madrid: Ediciones UNED.

Venegas, S. (2012) La imagen múltiple en la ilustración de libros para niños. Memoria gráfica, 5, 16-17.

Zúñiga Fuentes, E. (2007). Los indios en los relatos históricos del pasado de la nación. 160 años de textos escolares de Historia de Chile (1845 2005), pp. 176-182. Primer Seminario Internacional de Textos Escolares (SITE). Abril, 2006. Santiago de Chile.

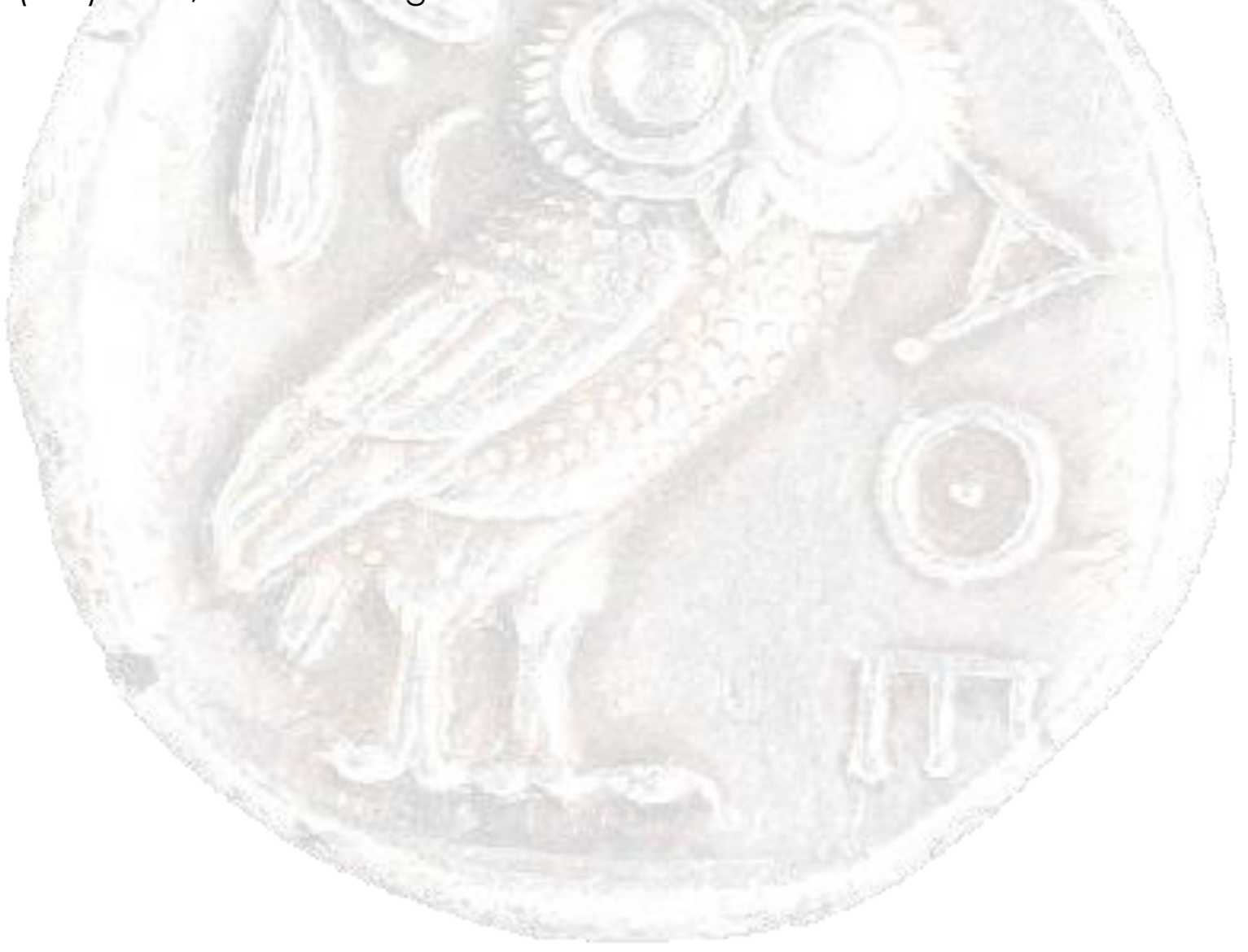

